\title{
The Effect of Fermentation and Drying Processes on Oil Absorption Capacity of Palm Fruit Mesocarp Fibre Flour
}

\author{
${ }^{1}$ Madu, O. U. \\ Nigeria Atomic Energy Commission, \\ Asokoro- Abuja, Nigeria
}

\author{
${ }^{2}$ Chukwu, O., ${ }^{2}$ Adejumo, B.A. \\ Department of Agricultural and Bioresources Engineering, \\ Federal University of Technology, Minna, Nigeria
}

\author{
${ }^{3}$ Abdulkareem, A.S. \\ Department of Chemical Engineering, \\ Federal University of Technology, Minna, Nigeria
}

\begin{abstract}
Tenera specie of oil palm fruits were fermented, dried, ground and sieved to obtain palm mesocarp fibre (PMF) flour. The effect of fermentation temperature, fermentation $\mathrm{pH}$, fermentation mass and fermentation time as well as drying temperature and drying time on oil absorption capacity (OAC) was examined. Results obtained showed that the highest value of OAC obtained in the study was $51 \%$ at the experimental conditions of fermentation temperature $\left(40^{\circ} \mathrm{C}\right), \mathrm{pH}(5.0)$, fermentation time (5 days), fermentation mass (60g), drying temperature $\left(45^{\circ} \mathrm{C}\right)$ and drying time (30 minutes).The result of the study also showed that fermentation and drying increased the moisture, crude protein and crude carbohydrate contents of the PMF while reducing crude fat and crude fibre contents of the PMF flour. Fermentation and drying processes proved to be useful tools in altering the nutritional content of the PMF flour produced.
\end{abstract}

Keywords: Fermentation, Drying, Palm Mesocarp Fibre

\section{INTRODUCTION}

Literatures have [1,2] reported that palm mesocarp fibre (PMF) are solid wastes generated from separating mesocarp fibre from other solid wastes obtained from processing oil palm fruits into crude palm oil (CPO). Small and medium scale (SMS) farmers are responsible for the processing of most oil palm fruits into CPO [3]. In Nigeria, individual household processors of CPO use the PMF as fuel for cooking and in steam boilers at the small and medium scale mills. Palm mesocarp fibre has also been used for bio-composite production [4]. The PMF can serve as is an attractive feed stock for dietary fibre because it is produced in large quantities from a renewable source [5] The PMF is also a lignocellulosic biomass that can be used as raw materials for fermentation processes [6].

Fermentation simply can be defined as a metabolic process concerned with the release of energy by cells for the conversion of carbohydrate into an acid or alcohol by microorganisms. Under favourable conditions fermentation can occur naturally in different foods materials and had been used for production of wine and beer [7]. According to [8] a fermenter is the main equipment used for fermentation. The fermenter is used to obtain a desired product under a controlled environment for the growth of a microorganism or a mixture of microorganisms. Microorganisms operate efficiently at certain temperature and $\mathrm{pH}$ conditions, an effective fermenter should provide these conditions while the rate of evaporation losses should not be in excess [7].

Oil absorption capacity (OAC) is associated with the chemical composition of plant polysaccharides [6]. Surface properties and hydrophobic nature of the plant material are the characteristics that determine the OAC of foods [20]. Flavour and mouth feel are the product parameters greatly affected by OAC [24].

\section{MATERIALS AND METHODS \\ A. Preparation of Palm Mesocarp Fibre}

Two kilograms (2kg) of fresh PMF from the tenera specie were obtained from processors of oil palm fruits in Isuochi, Umunneochi LGA, Abia State of Nigeria. The PMF samples were divided into two equal parts. One portion $(1 \mathrm{~kg})$ was fermented in an open vat for 7 days. The fermented PMF was dried using an oven Fermented and dried PMF samples were processed according to the experimental runs in Table 1 generated using Central Composite Design (CCD) method found within the Response Surface Design (RSD) using [12]. The other portion (1000g) which served as the control sample was oven dried to $14 \%$ moisture content. The dried fermented and control samples were grounded, hermetically sealed, and stored at room temperature.

The substrate solution used for the fermentation process was prepared using the method adapted by [9] at the experimental runs shown in Table 1. Glucose solution used as the substrate solution was prepared by dissolving $100 \mathrm{~g}$ of glucose in one litre of distilled water. To adjust the solution to become more acidic concentrated $\mathrm{HCl}$ was added into it and to make the solution more alkaline $\mathrm{NaOH}$ was added into it.

\section{B. Determination of the Oil Absorption Capacity}

The OAC was determined by the method adopted in [13]. One gramme (1g) of the fermented PMF samples was refined groundnut oil $(10 \mathrm{ml})$ to form a solution. The solution was stirred for 30 seconds. The fermented PMF samples stood for 30 minutes at $30^{\circ} \mathrm{C}$ in a water bath and centrifuged at 300rpm 
for 20 minutes. The supernatant volume value was noted. The supernatant volume value was used to calculate the WAC and OAC.

TABLE 1: EXPERIMENTAL RUNS FOR FERMENTATION AND DRYING PROCESSES

\begin{tabular}{|c|c|c|c|c|c|c|}
\hline Run & $\mathrm{A}$ & B & C & $\mathrm{D}$ & $\mathrm{E}$ & $\mathrm{F}$ \\
\hline 1 & 50 & 6 & 6 & 40 & 30 & 40 \\
\hline 2 & 50 & 4 & 4 & 40 & 30 & 40 \\
\hline 3 & 40 & 5 & 5 & 60 & 45 & 30 \\
\hline 4 & 40 & 5 & 5 & 12 & 45 & 30 \\
\hline 5 & 50 & 4 & 6 & 80 & 60 & 20 \\
\hline 6 & 63 & 5 & 5 & 60 & 45 & 30 \\
\hline 7 & 40 & 5 & 5 & 60 & 45 & 6 \\
\hline 8 & 30 & 6 & 4 & 40 & 30 & 40 \\
\hline 9 & 40 & 7 & 5 & 60 & 45 & 30 \\
\hline 10 & 30 & 6 & 6 & 80 & 30 & 40 \\
\hline 11 & 40 & 5 & 5 & 60 & 9 & 30 \\
\hline 12 & 30 & 4 & 6 & 80 & 60 & 40 \\
\hline 13 & 40 & 5 & 5 & 60 & 45 & 30 \\
\hline 14 & 30 & 6 & 4 & 40 & 60 & 20 \\
\hline 15 & 40 & 5 & 5 & 60 & 45 & 30 \\
\hline 16 & 30 & 4 & 4 & 80 & 60 & 20 \\
\hline 17 & 30 & 4 & 6 & 80 & 30 & 20 \\
\hline 18 & 30 & 4 & 6 & 40 & 60 & 20 \\
\hline 19 & 50 & 6 & 6 & 80 & 30 & 20 \\
\hline 20 & 40 & 2 & 5 & 60 & 45 & 30 \\
\hline 21 & 50 & 6 & 4 & 80 & 30 & 40 \\
\hline 22 & 40 & 5 & 5 & 60 & 45 & 53 \\
\hline 23 & 16 & 5 & 5 & 60 & 45 & 30 \\
\hline 24 & 30 & 6 & 6 & 80 & 60 & 20 \\
\hline 25 & 40 & 5 & 5 & 60 & 80 & 30 \\
\hline 26 & 40 & 5 & 5 & 60 & 45 & 30 \\
\hline 27 & 40 & 5 & 2 & 60 & 45 & 30 \\
\hline 28 & 30 & 6 & 6 & 40 & 30 & 20 \\
\hline 29 & 40 & 5 & 5 & 60 & 45 & 30 \\
\hline 30 & 30 & 6 & 4 & 80 & 60 & 40 \\
\hline 31 & 50 & 4 & 6 & 80 & 30 & 40 \\
\hline 32 & 50 & 6 & 4 & 40 & 30 & 20 \\
\hline 33 & 50 & 4 & 4 & 40 & 60 & 20 \\
\hline 34 & 50 & 6 & 6 & 80 & 60 & 40 \\
\hline 35 & 30 & 6 & 4 & 80 & 30 & 20 \\
\hline 36 & 40 & 5 & 5 & 60 & 45 & 30 \\
\hline 37 & 40 & 5 & 5 & 60 & 45 & 30 \\
\hline 38 & 30 & 4 & 4 & 40 & 60 & 40 \\
\hline 39 & 30 & 4 & 6 & 40 & 30 & 40 \\
\hline 40 & 50 & 6 & 4 & 80 & 60 & 20 \\
\hline 41 & 30 & 6 & 6 & 40 & 60 & 40 \\
\hline
\end{tabular}

\begin{tabular}{lllllll}
42 & 50 & 6 & 4 & 40 & 60 & 40 \\
43 & 40 & 5 & 5 & 60 & 45 & 30 \\
44 & 30 & 4 & 4 & 80 & 30 & 40 \\
45 & 50 & 4 & 6 & 40 & 30 & 20 \\
46 & 40 & 5 & 5 & 60 & 45 & 30 \\
47 & 50 & 4 & 6 & 40 & 60 & 40 \\
48 & 50 & 4 & 4 & 80 & 30 & 20 \\
49 & 40 & 5 & 7 & 60 & 45 & 30 \\
50 & 50 & 6 & 6 & 40 & 60 & 20 \\
51 & 50 & 4 & 4 & 80 & 60 & 40 \\
52 & 40 & 5 & 5 & 107 & 45 & 30 \\
53 & 30 & 4 & 4 & 40 & 30 & 20 \\
\hline
\end{tabular}

$\mathrm{A}=$ Fermentation Temperature $\left({ }^{\circ} \mathrm{C}\right), \mathrm{B}=$ Fermentation $p H, \mathrm{C}=$ Fermentation Time (days), $\mathrm{D}=$ Fermentation Mass (g), E=Drying Temperature $\left({ }^{\circ} \mathrm{C}\right)$, $\mathrm{F}=$ Drying Time (minutes)

\section{Proximate Composition of PMF Flour}

Proximate composition analysis for samples was conducted following the [10] method. The components analysed were moisture content; crude lipid; crude fibre; crude protein and ash. The results obtained were in triplicates and the mean values were used for the analysis.

\section{RESULTS AND DISCUSSIONS}

A. Effect of Fermentation Temperature on Oil Absorption Capacity

The result of the effect of fermentation temperature OAC in this study is illustrated in Figure 1. The highest fermentation temperature of $40^{\circ} \mathrm{C}$ was obtained in this study. The result obtained in the study could be linked to microbial activity which is at their best at temperatures within and slightly above room temperature. [11] reported that fermentation process can occur at different temperatures depending on the environmental conditions. The temperature range according to [14] where the highest rates of fermentation occur is from $30^{\circ} \mathrm{C}$ to $45^{\circ} \mathrm{C}$. The finding of this study is within the proximity of fermentation temperature range as observed by [15]. [14] also reported that at fermentation temperature above $50^{\circ} \mathrm{C}$ stress is induced on microbial activity in a multi microorganism environment.

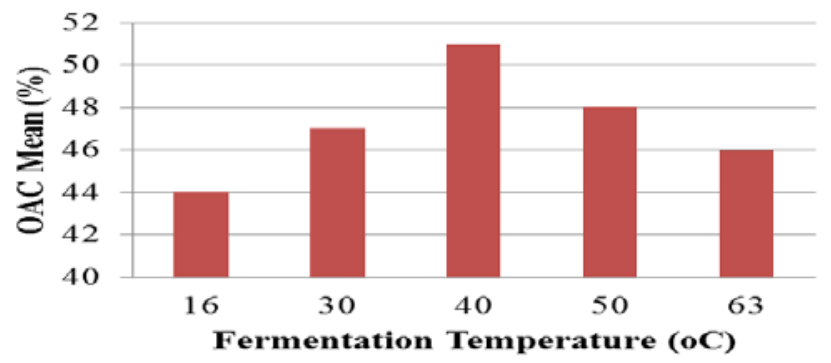

Figures 1: Effect of fermentation temperature on oil absorption capacity

\section{B. Effect of Fermentation pH on Oil Absorption Capacity}

The result obtained in the study from the effect of fermentation $p H$ from 2.0 to 7.0 is shown in Figure 2. Figure 2 indicates that the $\mathrm{pH}$ value of 5 gave the highest value for OAC. The OAC values increased between the $p H$ of 2.0 to 5.0 and decreased thereafter. Microbial activity is a function of the acidity or 
alkalinity of the reaction medium. [15] and [9] reported that as the $p H$ of a reaction medium moves from acidic to alkaline the microbial enzymes that catalyse the metabolism of glucose losses their ability to function efficiently. The trend observed from the result of this study could be because enzymes that facilitate the metabolism of glucose functions are known to be more effectively in an acidic condition [14]. The result of this study shows close agreement to [9] that reported the $\mathrm{pH}$ of 4.0 to 5.0 as the optimum $\mathrm{pH}$ range for any fermentation processes.

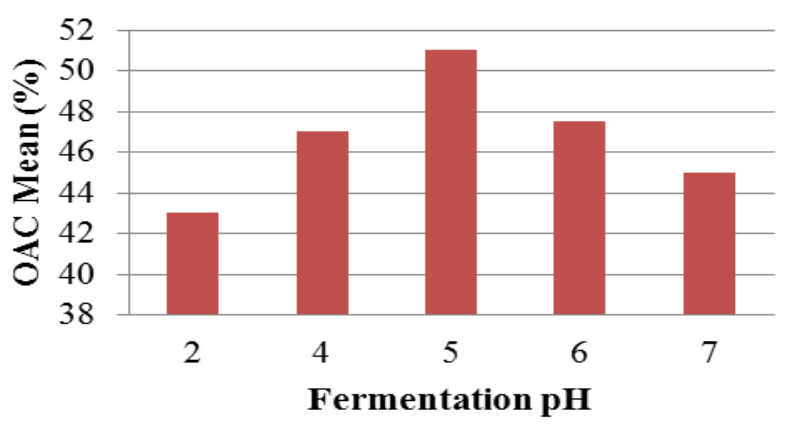

Figures.2: Effect of $p H$ on oil absorption capacity

\section{Effect of Fermentation Time on Oil Absorption Capacity}

The result of the effect of fermentation time on OAC obtained in this study is shown in Figure 3. The result of the study indicated that the OAC value increased from $40 \%$ (2days) to $51 \%$ (5 days) and then decreased to $45 \%$ (7 days). The highest value for OAC was recorded after 5 days of fermentation. The result obtained from the study indicates that the $5^{\text {th }}$ day marked the apex of the exponential growth rate when there was little or no stress on microbial activity due to unfavourable conditions of competing reactions for substrates and production of undesirable products [17]. The result of this study is closely related to [18] who noted 5 days as the optimal number of days required for a fermentation process.

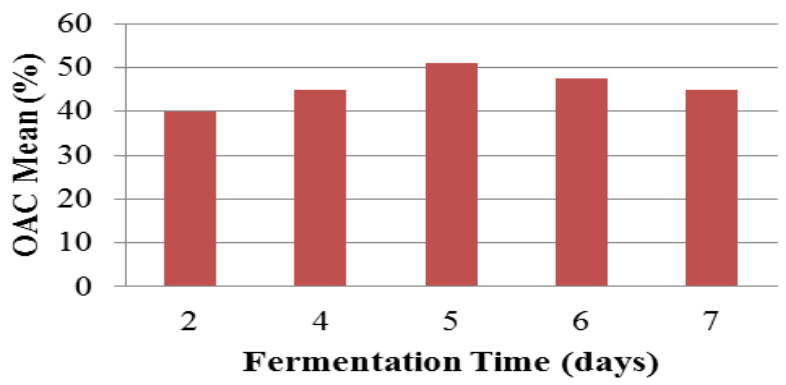

Figures 3: Effect of fermentation time on oil absorption capacity

\section{Effect of Fermentation Mass on Oil Absorption Capacity}

Results presented in Figure 4 from the study reveals that fermentation mass of $60 \mathrm{~g}$ gave the highest value for OAC. The result obtained in this study indicates that below and above $60 \mathrm{~g}$ fermentation mass there was a reduced percent yield of OAC. [16] and [9] observed that during a fermentation process the feedstock mass of the material to be fermented determines the outcome of the yield result. The pattern of result observed in the study could be attributed to the fact that microbial activity during the fermentation process was overwhelmed by the either high or low substrate concentration. High fermentation masses beyond the optimum fermentation mass also showed reduced values for OAC. This is an indication that the microbial activity was overwhelmed by reduced substrate concentration. The optimum fermentation mass pattern in this study shows proximity with the works of [16] and [11] in their study of bioethanol yield from biomass.

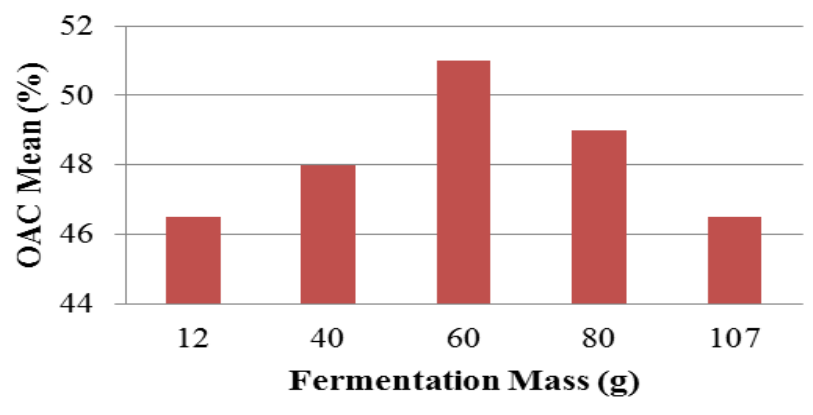

Figures 4: Effect of fermentation mass on oil absorption capacity

\section{E. Effect of Drying Temperature on Oil Absorption Capacity} The highest values for OAC were obtained in this study at a drying temperature of $45^{\circ} \mathrm{C}$ as shown Figure 5 . This pattern of result could be attributed to the increase in the soluble dietary fibre and change in the starch and amino acid content of the PMF. The drying temperature of $45^{\circ} \mathrm{C}$ obtained in this study is within the proximity of temperature range observed by [19] and [20] in their study of blueberry liquids and chia seeds respectively. It also agrees with work of [21] which reported that heat processing led to an increase in non-polar amino acid and soluble dietary fibre thus increasing the presence of hydrophilic starch content.

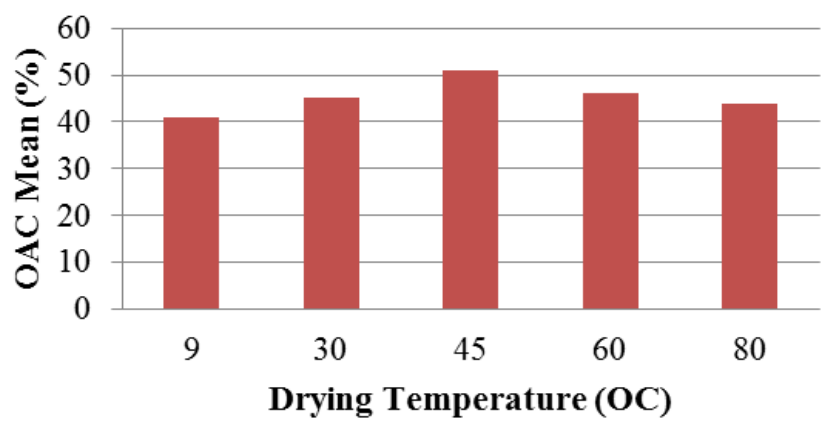

Figures 5: Effect of drying temperature on oil absorption capacity

\section{F. Effect Drying Time on Oil Absorption Capacity}

The effect of drying time on OAC in this study is as presented in Figures 6. The result of the study shows that the highest values for OAC were obtained at a drying time of 30 minutes. According to [22] the effectiveness and efficiency of a drying process is dependent on processing time. The results obtained from this study can be ascribed to the quality of starch in the $\mathrm{PMF}$ and the retention of moisture with more hydrophobic groups within the matrix of the PMF being analysed. The result of this work shows an agreement to [23]; [11] and [16] that reported similar drying processing time for agro-waste fibrous materials. 


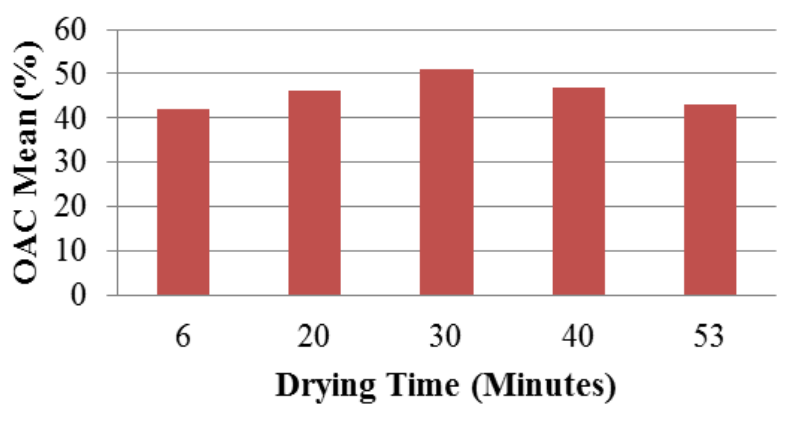

Figures 6: Effect of drying time on oil absorption capacity
G. Effect of Fermentation and Drying on Proximate Composition of PMF Flour

The results of this study on the proximate composition of the PMF are presented in Table 2. The results on proximate composition of the flour showed that different parameters were affected differently by the length of fermentation. An increase in the number of fermentation days resulted in gradual increase in moisture content, crude fat and crude fibre. The dry matter of the PMF was on the decrease from 83.81\% (unfermented $\mathrm{PMF}$ ) to $80.60 \%$ (fermented PMF) as the moisture content increased from $16.19 \%$ (unfermented PMF) to $19.40 \%$ (fermented PMF). The moisture content of food products determines how long they store at room temperature [20].

The obtained result can be associated with the conversion of the more of the fibre content of the PMF into soluble dietary fibre and the drying processing method used for drying the PMF flour. According to [24] fermentation increases the soluble dietary fibre content of food material.

TABLE 2: PROXIMATE COMPOSITION OF THE PMF FLOUR

\begin{tabular}{|c|c|c|c|c|c|c|c|}
\hline \multirow[t]{2}{*}{ Constituent } & \multirow[t]{2}{*}{ unfermented } & \multicolumn{6}{|c|}{ Fermented Oil Palm Mesocarp Fibre } \\
\hline & & Day 1 & Day 2 & Day 3 & Day 4 & Day 5 & Day 6 \\
\hline Moisture Content (\%) & $16.19 \pm 0.31^{\mathrm{a}}$ & $17.67 \pm 0.13^{\mathrm{a}}$ & $19.3 \pm 0.12^{\mathrm{b}}$ & $19.4 \pm .18^{\mathrm{b}}$ & $19.4 \pm 0.18^{b}$ & $19.4 \pm 0.18^{b}$ & $19.4 \pm .18^{\mathrm{b}}$ \\
\hline $\begin{array}{l}\text { Crude Carbohydrate } \\
\text { (\%) }\end{array}$ & $25.14 \pm 2.11^{\mathrm{a}}$ & $24.69 \pm 1.38^{\mathrm{a}}$ & $25.40 \pm 1.77^{\mathrm{a}}$ & $25.79 \pm 2.06^{\mathrm{a}}$ & $26.12 \pm 3.13^{\mathrm{a}}$ & $26.12 \pm 3.13^{\mathrm{a}}$ & $26.12 \pm 3.13^{\mathrm{a}}$ \\
\hline Crude Protein (\%) & $3.35 \pm 0.14^{\mathrm{a}}$ & $3.29 \pm 0.11^{\mathrm{ab}}$ & $4.03 \pm 0.17^{\mathrm{b}}$ & $4.43 \pm 0.26^{c}$ & $4.84 \pm 0.34^{\mathrm{c}}$ & $4.84 \pm 0.34^{\mathrm{c}}$ & $4.84 \pm 0.34^{\mathrm{c}}$ \\
\hline Crude Fibre (\%) & $17.60 \pm 0.02^{\mathrm{a}}$ & $17.28 \pm 0.04^{\mathrm{b}}$ & $16.53 \pm 0.24^{\mathrm{b}}$ & $16.12 \pm 0.05^{\mathrm{bc}}$ & $15.72 \pm 0.07^{\mathrm{bc}}$ & $15.72 \pm 0.07^{\mathrm{bc}}$ & $15.72 \pm 0.07^{\mathrm{bc}}$ \\
\hline Crude Fat (\%) & $30.17 \pm 0.03^{\mathrm{a}}$ & $29.63 \pm 0.16^{\mathrm{a}}$ & $27.40 \pm 0.15^{\mathrm{ab}}$ & $26.60 \pm 0.06^{\mathrm{b}}$ & $26.20 \pm 0.06^{\mathrm{b}}$ & $26.20 \pm 0.06^{\mathrm{b}}$ & $26.20 \pm 0.06^{\mathrm{b}}$ \\
\hline Ash (\%) & $7.54 \pm 0.11^{\mathrm{a}}$ & $7.41 \pm 0.23^{\mathrm{a}}$ & $7.25 \pm 0.04^{\mathrm{b}}$ & $7.25 \pm 0.04^{b}$ & $7.25 \pm 0.04^{b}$ & $7.25 \pm 0.04^{b}$ & $7.25 \pm 0.04^{b}$ \\
\hline
\end{tabular}

Means \pm SE $(\mathrm{N}=3)$ means in the column with same superscript differ not significantly $(\mathrm{p}<0.05)$

A decrease from $17.60 \%$ (unfermented PMF) to $15.72 \%$ (fermented PMF) for crude fibre was observed in this study. The study's result for the crude fibre can be credited to degradation of hemicellulose, cellulose, and lignin into soluble dietary fibre fraction during fermentation. This trend of result agrees with [25] Lario et al. (2004) that reported similar results from processing of agro-waste fibrous materials.

The crude fat from this study decreased from $30.17 \%$ to $26.20 \%$. The observed decrease can also be attributed to the presence of more hydrophilic amino acids and the fact that fermentation produces mainly short-chain fatty acids that are easily utilised by lipolytic microorganisms. [15], noted that fermentation resulted in the use of short chain fatty acids as feedstock by lipolytic microorganisms.

There was an increase in the crude carbohydrate and crude protein from $25.14 \%$ to $26.12 \%$ and $.35 \%$ to $4.84 \%$ respectively. The incremental trend for crude carbohydrate and crude protein as reported in this study can be attributed to the degradation of the starch in the fibrous material and increase in the microbial load respectively. This finding agrees with range of values in the work of [1] who reported crude carbohydrate and crude protein values of 25\% and 3\% respectively for PMF.

There were no significant differences in ash content from the study. The major minerals in the PMF as observed in the study is phosphorous and calcium. The ranges of values for these minerals are similar to those reported also in [1].

\section{CONCLUSION}

The result from the study indicated that the use of fermentation and drying processes modified the structure of PMF flour produced. Fermentation and drying processes resulted in the production of PMF flour with good oil absorption capacity. The PMF flour showed decreases in crude fat and crude fibre while there were increases in moisture content, crude protein and crude carbohydrate. The ash content of the PMF flour was constant. The PMF flour produced from the study thus could serve as raw materials for food product formulations. 


\section{REFERENCES}

[1] Marsin-Sanagi, M., See, H.H., Ibrahim W.A.W., Abu Naim, A. (2005). Determination of carotene, tocopherols and tocotrienols in residue oil from palm pressed fiber using pressurized liquid extraction-normal phase liquid chromatography, AnalyticaChimica Acta 5(38): 71-76

[2] Food and Agriculture Organization of the United Nations (FAO), (2006) Food and AgricultureBulletin on FoodSecurity. www.fao.org/docrep/x5030E/X15032E06.htm

[3] Ajani, E. N., Onwubuya, E. A. and Nwalieji, H. U., (2012). Assessment of oil palm production and processing among rural women in Enugu North agricultural zone of Enugu State, Nigeria. International Journal of Agricultural Sciences. 2 (12) 322-329.

[4] Neoh, B. K., Thang, Y. M., Zain, M. Z. M. and Junaidi, A. (2011). Palm pressed fibre oil: A new opportunity for premium hardstock? International Food Research Journal 18: 769-773

[5] Teh, C.C., Ibrahim, N.A., and Wan Yunus, W.M.Z., (2013) Response surface methodology for the optimization and characterization of oil palm mesocarp fiber-graftpoly(butylacrylate). BioResources, 8, 5244-5260.

[6] Kumar, V., Sinha, A.K., Makkar, H.P.S., De Boeck, G., and Becker, K. (2012). Dietary roles of non-starch polysachharides in human nutrition. Critical Reviews in Food Science and Nutrition,52:899-935

[7] Flander, L. (2012). Bioprocessing to improve oat bread quality. VTT Science 8. PhD Thesis, University of Helsinki. Espoo: VTT Technical Research Centre of Finland, Finland.

[8] Gerpen, J.V., (2007). Biodiesel production and fuel quality. University of Idaho, Moscow.

[9] Mohammed, D., Mohammed, I.G. and Muazu, K. (2011). Optimum Hydrolysis-Fermentation Parameters for the Production of Bioethanol from the Nigerian Stem Juice of Sweet Sorghum.Petroleum Technology Development Journal, 7(1), 64-73

[10] Association of Official Analytical Chemists AOAC, (2005) Official Methods of Analysis (18thedn.)

[11] Mutreja, R., Das, D., Goyal, D. and Goyal, A. (2011). Bioconversion of agricultural waste to ethanol by SSF using recombinant cellulose from (Clostridium thermocellum), Enzyme Research, vol. 2011, 1-6

[12] Minitab Inc. (2010) Minitab Statistical Software, Release 17 for Windows, State College, Pennsylvania, USA

[13] Kamaljit, K., Amarjeet, K., and Pal, S.T. (2011). Analysis of ingredients, functionality, formulation optimization and shelf life evaluation of high fiber bread.America Journal of Food Technology, 6 (4): 306-313

[14] Liang, Y., Feng, Z., Yesuf, J., and Blackburn, J. W. (2010). Optimization of growth medium and enzyme assay conditions for crude cellulases produced by a novel thermophilic and cellulolyticn bacterium, (Anoxybacillussp) Applied Biochemistry and Biotechnology, vol. 160, no. 6, pp. 1841-1852

[15] Bandaru, V. V. R., Somalanka, S. R., Mendu,D. R. N., Madicherla, R., and Chityala, A. (2006). Optimization of fermentation conditions for the production of ethanol from sago starch by coimmobilizedamyloglucosidase and cells of Zymomonasmobilis using response surface methodology, Enzyme and Microbial Technology, vol. 38, no.1-2, pp. 209214

[16] Reddy, Y. H. K., Srijana, M., Reddy, D. M., and Gopal, R. (2010) Coculture fermentation of banana agro-waste to ethanol by cellulolytic thermophilic Clostridium thermocellumCT2, African Journal of Biotechnology, vol. 9, no. 13, pp. 1926-1934
[17] K'ad'ar, Z., Szengyel, Z., and R'eczey, K. (2004). Simultaneous saccharification and fermentation (SSF) of industrial wastes for the production of ethanol, Industrial Crops and Products, vol. 20, no. 1, 103-110

[18] Selinheimo, E., Kruus, K., Buchert, J., Hopia, A., and Autio, K., (2006). Effects of laccase, xylanase and their cosmbination on the rheological properties of wheat doughs. Journal of Cereal Science, Vol. 43, No. 2, pp. 152-159.

[19] Chakraborty, M., Savarese, M., Harbertson, E., Harbertson, J., and Ringer, K., (2010). Effect of the Novel Radiant Zone Drying Method on Anthocyanins and Phenolics of Three Blueberry Liquids. Journal of Agric. Food Chem. Volume 58(1), pp324-330.

[20] Capitani, M.I., Spotorno, V., Nolasco, S.M. and Tomas, M.C. (2012). Physicochemical and functional characterization of by-products from chia (Salvia hispanica L.) seeds of Argentina. LWT-Food Science and Technology. 45. 94-102

[21] Mahadevamma, S. and Tharanathan, R. N. (2004)."Processing Of Legumes: Resistant Starch and Dietary Fiber Contents." Journal of Food Quality 27(4): 289-303.

[22] Mujumdar, A.S. (2007). Handbook of industrial drying. CRC Press. p.710.ISBN1-57444-6681.http://books.google.com [23] Chukwuneke, J.L., Achebe, C.H., Okafor, E.A., and Okolie, P.C. (2013). The Effect of Variety and Drying on the Engineering Properties of Fermented Ground Cassava. International Journal of Scientific Knowledge, 1(5): 13-27

[23] Bhatt, S.M., and Gupta, R.K., (2015). Bread (composite flour) formulation and study of its nutritive, phytochemical and functional properties. Journal of Pharmacognosy and Phytochemistry; 4(2): 254-268

[24] Lario, Y., Sendra, E., García-Perez, J., Fuentes, C., SayasBarbera, E., Fernandez-Lopez, J. and Pérez-Alvarez, J. A., (2004). Preparation of high dietary fiber powder from lemon juice by-product. Innovative Food Science and Emerging Technologies 5, 113-117 